\title{
IN VITRO FREE RADICAL SCAVENGING ACTIVITY AND IN VIVO ANTICATARACT POTENTIAL OF HEMIDESMUS INDICUS ROOTS IN STREPTOZOTOCIN INDUCED DIABETIC RATS
}

\author{
PRABHAKAR TIRUMANI*, RAJASHEKHAR AV \\ Department of Zoology, Physiology Division, Osmania University, Hyderabad, Telangana, India. Email: prabhu.venkat2010@gmail.com
}

Received: 07 July 2017, Revised and Accepted: 18 August 2017

ABSTRACT

Objective: Hemidesmus indicus R. Br. (HI) (Indian sarsaparilla) is traditionally used in Indian medicine for human therapy. The present study was aimed to evaluate the antioxidant activity of $\mathrm{HI}$ root extracts, and its effects on delaying (or) management of cataract progression in streptozoticin (STZ) induced diabetic rats.

Methods: The plant roots were extracted in different solvents, estimated total phenolic content, total flavonoid content and conducted free radical scavenging potential through 1,1-Diphenyl-2-picrylhydrazyl (DPPH), 2,2 azinobis (3-ethyl benzothiazoline-6-sulphonic acid diammonium salt (ABTS) $\mathrm{NO}, \mathrm{OH}$ and reducing power assays. Further, the protective effect was evaluated in STZ induced diabetic rats through administered of ethyl acetate extract of HI (200 and $400 \mathrm{mg} / \mathrm{kg}$ body weight) orally for 8 weeks to study its effect on oxidative stress and diabetic cataract progression.

Results: In primary results demonstrated that the ethyl acetate extract has been showed considerable free radical scavenging activity and significantly gain body weight, gradual decreasing blood glucose levels and delay cataract progression has been observed in HI treated rats. Furthermore, we observed significantly decreased oxidative stress markers, and restoration of the antioxidant system in HI treated rats. Lens sections from experimental animal again evidenced to conform the ameliorative effect of $\mathrm{HI}$ on diabetic cataract.

Conclusion: This obtained result's confirmed that the protective effect of $\mathrm{HI}$ is attributed to the antioxidant activities of plant roots and its active principles.

Keywords: Hemidesmus indicus, Free radicals, Antioxidant activity, Streptozotocin, Diabetic cataract.

(c) 2017 The Authors. Published by Innovare Academic Sciences Pvt Ltd. This is an open access article under the CC BY license (http://creativecommons. org/licenses/by/4. 0/) DOI: http://dx.doi.org/10.22159/ajpcr.2017.v10i12.21167

\section{INTRODUCTION}

Diabetic cataract, characterized by progressive opacification of the transparent eye lens, which is a part of the earliest secondary complication of diabetes [1]; leading to visual impairment and blindness worldwide predominantly in developing countries like India [2,3]. Due to the high prevalence of these countries, a diabetic cataract may pose a major problem in the management of blindness [4]. Evidence demonstrates that both the hyperglycemia and oxidative stress are well known for increase the burden of cataract formation by various risk factors [5]. Long-term hyperglycemia achieves greater oxidative stress by producing reduced sugars, and these reducing sugars react with lipids and proteins causing the cumulative production of reactive oxygen species (ROS) [6,7]. ROS are oxygen-derived free radicals such as hydroxyl radicals $(\mathrm{OH} \bullet)$, superoxide anion $\left(\mathrm{O}_{2}\right)$, hydroperoxyl $(\mathrm{OOH} \bullet)$, peroxyl $(\mathrm{ROO} \bullet)$, and alkoxy ( $\mathrm{RO} \bullet)$ and as well as singlet oxygen $\left({ }^{1} \mathrm{O}_{2}\right)$ [8]. Moreover, ROS could cause oxidative damages to biological macromolecules (proteins, lipids, DNA, etc.) which lead to degenerative processes and chronic diseases such as diabetic cataract $[9,10]$. Antioxidant compounds can prevent (or) repair the body's cells, especially through free radical scavenging, reducing agents, complexes of pro-oxidant metals and quenching of singlet oxygen. Consequently, increase the antioxidant capacity of the plasma and reduce the risk of diseases $[11,12]$.

In recent times attention toward finding natural antioxidants have been significantly increased to replace synthetic antioxidants as medicinal products [13], which are said to be toxic to animals including human beings and the exploitation of the various secondary metabolites of the plants was highlighted. Plants constitute the main source of natural antioxidant molecules (phenols and flavonoids) which have the capacity to neutralize the ROS [14] and protect the human body from free radicals and retard the progress of many chronic diseases $[15,16]$. Scientific examination and validation of the traditional therapeutic use of the plant medicines may be transelated of new and effective drugs as occurred in the past. The continued search for natural antioxidants has gained importance in recent years because of the improving awareness of herbal remedies for various chronic diseases [17].

Hemidesmus indicus (L.) R. Br. (HI), belonging to family Asclepiadaceae, locally known as anantamul, twining shrub that has been used as folk medicine, Unani preparations, Indian Ayurveda system and its roots were used extensively to treat the different types of diseases in humans [18]. The root of HI considered to be demulcent, diaphoretic, diuretic, tonic and also utilized in loss of appetite, fever, skin diseases, leucorrhea, syphilis, and rheumatism. Earlier studies reported that an alcoholic extract of its roots possesses antithrombotic, antihepatotoxic, antinociceptive, anti-inflammatory, renoprotective, antidiarrheal, and antienterobacterial activities [19-23] and is found to be effective in the control of blood glucose levels through restoration of insulin production $[24,25]$. The root has been used for treating blood diseases, diarrhea, respiratory disorders, skin diseases, syphilis, fever, bronchitis, asthma, eye diseases, epileptic fits in children, kidney and urinary disorders, loss of appetite, burning sensation, rheumatism, and in gastric ailments [26,27]. Hence compounds, which can scavenge the excess of free radicals formed or inhibit their production or protect membranes from peroxidation [28]. However, the pharmacological effect of HI against secondary diabetic complications such as cataract has still not been studied. Therefore, in the present study evaluates that the antioxidant property of $\mathrm{HI}$ and its role in delaying cataract progression in streptozotocin (STZ) induced diabetic rats. 


\section{MATERIALS AND METHODS}

\section{Materials}

STZ, quercetin, 1,1-diphenyl-2-picrylhydrazyl (DPPH), and 2,2 azinobis (3-ethyl benzothiazoline-6-sulphonic acid diammonium salt (ABTS) obtained from Sigma-Aldrich (MO, USA) and sodium carbonate, sodium phosphate, potassium ferrocyanide, ascorbic acid, gallic acid, potassium persulfate, and Folin-Ciocalteu reagent were purchased from Merck Pvt Ltd (Mumbai, India). Riboflavin, nitro blue tetrazolium, pyrogallol and other reagents, analytical grade chemicals and solvents were obtained from SD Fine Chemicals, India, and indigenous companies in India.

\section{Collection and preparation of plant material}

The roots of the plant HI were collected in July 2014 from the Nallamala forest, Mahaboob Nagar district, Telangana state, India. The plant was identified and authenticated by the chief taxonomist, Prof, P. Ramachandra Reddy, Department of Botany, Osmania University, Hyderabad, and a voucher specimen (Bat/OU/0119/HYD) was deposited in the department of botany for further reference. The roots of HI have been dried under shade for 1 month and powdered in a mechanical grinder into a coarse powder. About $300 \mathrm{~g}$ of powder was macerated in $1.5 \mathrm{l}$ of four different solvents (methanol, ethyl acetate petroleum ether, and distilled water) in a dark room at room temperature for 5-8 days with intermittent shaking. The solvent extracts were filtered and then concentrated using a rotary evaporator and kept in a vacuum desiccator for complete removal of the solvent to yield a semi solid mass. The crude extracts were weighed and stored in the refrigerator until further use.

\section{Determination of total phenolic content (TPC)}

The TPC of each plant extract was determined using the FolinCiocalteu reagent according to the method described by Ainsworth and Gillespie [29]. In this method, a volume of $1 \mathrm{ml}$ of the plant extract $(1 \mathrm{mg} / 1 \mathrm{ml}$ ) was added to $2 \mathrm{ml}$ of Folin-Ciocalteu reagent (diluted 1:10 with distilled water) and was neutralized with $2 \mathrm{ml}$ of $20 \%$ sodium carbonate solution. The mixture was permitted to incubate at room temperature for 30 minutes with intermittent shaking for color development. Then, the absorbance of the resulting blue color was measured at $765 \mathrm{~nm}$ using a double beam UV-VIS spectrophotometer (Hitachi U-2910). The TPC of all the extracts was determined by the linear equation of a standard curve prepared with gallic acid and calculated as mean \pm standard deviation $(\mathrm{SD})(\mathrm{n}=3)$ and expressed as mg GAE/g dry extract.

\section{Estimation of total flavonoid content (TFC)}

TFC was determined using the form of a flavonoid-aluminum complex by a spectrophotometric assay as described earlier, with some modifications [30]. A volume of $0.5 \mathrm{ml}$ of the plant extract (1 mg) was mixed with $0.1 \mathrm{ml}$ of $10 \%$ aluminum chloride, $0.1 \mathrm{ml}$ of potassium acetate $(1 \mathrm{M})$, and $4.3 \mathrm{ml}$ of $80 \%$ methanol were mixed. The reaction mixture was incubated at room temperature for 30 minutes for color development. The absorbance was measured at $415 \mathrm{~nm}$ using UV-VIS spectrophotometer (Hitachi U-2910). The calculation of total flavonoids in the extracts has been determined from the linear equation of a standard curve prepared with quercetin and calculated as mean $\pm \mathrm{SD}$ $(n=3)$ and expressed mg QE/g of dry extract.

\section{Scavenging of DPPH radical}

The effect of HI extracts on DPPH radical has been carried out, employing the method described earlier by Huang et al., 2011 [31]. DPPH is a molecule containing a stable free radical, and in the presence of an antioxidant, which can donate an electron to DPPH, the purple color typical for free DPPH radical decays and the absorbance change is measured at $\lambda=517 \mathrm{~nm}$. Briefly, the assay mixture contained $2 \mathrm{ml}$ of $0.004 \%$ DPPH solution prepared in methanol and $0.2 \mathrm{ml}$ of standard (or) sample solution of various concentrations $(5-300 \mu \mathrm{g} / \mathrm{ml})$ in methanol. The mixture was shaken vigorously and allowed to stand at room temperature for 30 minutes, and the absorbance of the resulting solution was measured at $517 \mathrm{~nm}$ using a spectrophotometer (Hitachi
U-2910). The radical scavenging activity was measured as a decrease in the absorbance of DPPH and was calculated using the following formula:

DPPH scavenging activity $(\%)=\left(A_{\text {control }}-A_{\text {Sample }}\right) / A_{\text {Control }} \times 100$

Nitric oxide (NO) scavenging activity assay

Griess Ilosvay reaction is used to determine the nitrite ions which are generated by aqueous sodium nitroprusside solution interacts with oxygen and NO at physiological pH [32]. The pink chromophore formed of the reaction mixture was read at $546 \mathrm{~nm}$ against the blank. The percentage inhibition of activity was calculated using the following formula:

NO scavenging activity $(\%)=\left(\mathrm{A}_{\text {control }}-\mathrm{A}_{\text {Sample }}\right) / \mathrm{A}_{\text {Control }} \times 100$

The extract concentration providing $50 \%$ inhibition $\left(\mathrm{IC}_{50}\right)$ was calculated and obtained by interpolation from a linear regression analysis.

\section{Hydroxyl radical scavenging activity}

The reaction mixture, containing $\mathrm{HI}$ extracts $(0-300 \mu \mathrm{g} / \mathrm{ml})$, was incubated with EDTA $\left.(0.1 \mathrm{mmol}), \mathrm{FeCl}_{3} 0.1 \mathrm{mmol}\right), \mathrm{H}_{2} \mathrm{O}_{2}(1 \mathrm{mmol})$, deoxyribose $(3.75 \mathrm{mmol})$, and ascorbic acid $(0.1 \mathrm{mmol})$ in potassium phosphate buffer $(20 \mathrm{mmol}, \mathrm{pH} 7.4)$ for 60 minutes at $37^{\circ} \mathrm{C}$ [33]. The reaction was terminated by adding $1.0 \mathrm{ml}$ of trichloroacetic acid $(2 \% \mathrm{w} / \mathrm{v}), 1.0 \mathrm{ml}$ of thiobarbituric acid (TBA) $(1 \% \mathrm{w} / \mathrm{v})$ and then heating the tubes in boiling water 15 minutes. The contents have been cooled to develop the pink color measured at $535 \mathrm{~nm}$ against the blank. Decreased absorbance of the reaction mixture indicates increased antioxidant activity.

\section{Determination of ABTS radical scavenging activity}

The free radical scavenging activity of $\mathrm{HI}$ was measured by discoloration of $\mathrm{ABTS}^{+}$radical cation using the modified method [34]. ABTS radical cation $\left(\mathrm{ABTS}^{+}\right)$was produced by oxidation of ABTS $(7 \mathrm{mM})$ with potassium persulfate $(2.4 \mathrm{mM})$. Plant extracts $(1 \mathrm{ml})$ have been allowed to react with $2.5 \mathrm{ml}$ of ABTS solution $(0.703 \pm 0.005$ at $734 \mathrm{~nm})$, and ascorbic acid was used as a standard. Percentage inhibition was calculated using this formula:

ABTS radical scavenging activity $=\left(\mathrm{A}_{\text {Control }}-\mathrm{A}_{\text {Sample }}\right) / \mathrm{A}_{\text {Control }} \times 100$

Where, $\mathrm{A}_{\text {contro }}$ is the absorbance of ABTS radical with methanol and $\mathrm{A}_{\text {Sample }}$ is the absorbance of ABTS radical with extract/standard and data expressed mean $\pm S D(n=3)$.

\section{Determination of reducing power}

The reducing power of the plant extracts was determined using the earlier described method [35]. Briefly, different amount of extract (0$300 \mu \mathrm{g}$ ) in $1 \mathrm{ml}$ of methanol was mixed with $2.5 \mathrm{ml}$ of phosphate buffer $(0.2 \mathrm{M}, \mathrm{pH} 6.6), 2.5 \mathrm{ml}$ of potassium ferricyanide (10\%). The reaction mixture was incubated at $50^{\circ} \mathrm{C}$ for 20 minutes after centrifugation for 10 minutes at $3000 \mathrm{rpm}$. Further $2.5 \mathrm{ml}$ of the supernatant solution, $2.5 \mathrm{ml}$ of distilled water and $0.5 \mathrm{ml}$ of $\mathrm{Fecl}_{3} 0.1 \%$ freshly prepared) were mixed properly, and absorbance was read at $700 \mathrm{~nm}$. Increased absorbance indicating stronger reducing power and the results have been compared with that of the rutin as standard.

\section{Experimental animals and treatment}

2-month-old male Sprague-Dawley rats with an average body weight of $180 \pm 8$ g (obtained from the National Center for Laboratory Animal Sciences, National Institute of Nutrition, Hyderabad, India.) have been used for this study under standard laboratory conditions. All the animals were fed with a semi synthetic AIN-93 diet [14] and water ad libitum throughout the experimental period. Animal care and experimental protocols were approved by the Institutional Animal Ethical Committee. Diabetes mellitus has been induced using an intraperitoneal injection of STZ, at a single dose of $35 \mathrm{mg} / \mathrm{kg}$ body weight dissolved in $0.1 \mathrm{M}$ citrate buffer ( $\mathrm{pH} 4.5$ ). The 
fasting blood glucose levels were monitored, and these levels over than $200 \mathrm{mg} / \mathrm{dl}$ have been considered as diabetic model rats.

The experiment was carried out in four groups of eight rats each:

- Group I: Control rats (received sham, $0.1 \mathrm{M}$ citrate buffer, $\mathrm{pH} 4.5$ )

- Group II: Diabetic control (STZ induced, single i.p. $35 \mathrm{mg} / \mathrm{kg}$ bw)

- Group III: Diabetic rats, administered orally with ethyl acetate extract of HI (EAHI) at a low dose (200 mg/kg bw/day)

- Group IV: Diabetic rats, administered orally with EAHI at a high dose ( $400 \mathrm{mg} / \mathrm{kg} \mathrm{bw} /$ day)

Blood glucose level was recorded using glucose monitoring system (Dr Morepen GlucoOne kit) once a week after an overnight fasting. The body weights have been taken using a digital balance and cataract progression were monitored on a weekly basis using a slit lamp microscope (VISIL 02 Excel) [5].

\section{Preparation of lens homogenate}

At the end of the experimental period ( $8^{\text {th }}$ week), the rats were sacrificed by $\mathrm{CO}_{2}$ asphyxiation, and the lenses were dissected by posterior approach then placed into pre-weighed Eppendorf tubes and frozen at $-80^{\circ} \mathrm{C}$ until further analysis. A $10 \%$ homogenate was prepared from the lens in $50 \mathrm{mM}$ phosphate buffer ( $\mathrm{pH} 7.4)$ and the activity of the lens enzymes and soluble protein was measured in the soluble fraction of the lens homogenate $\left(15,000 \times \mathrm{g}\right.$ at $4^{\circ} \mathrm{C} / 20$ minutes) while the lens TBA reactive substances (TBARS) levels and total protein have been determined in the total homogenate.

\section{Estimation protein content and in vivo antioxidant levels}

The reduced glutathione (GSH) was estimated by the method of Ellman, 1959 [36]. The total reaction was measured at $412 \mathrm{~nm}$ against blank and values were compared with a standard curve of GSH. Lipid peroxidation is based on the reaction of malondialdehyde with TBA to form TBARS, which have a pink color with absorption maxima at $540 \mathrm{~nm}$ and TBARS levels in the lens homogenate has been analyzed using the method of Matsunami et al. [37]. Protein carbonyl groups were estimated by the earlier described method [38], and the concentration of protein carbonyls was calculated using a molar extinction coefficient $\left(\varepsilon 365 \mathrm{~nm}=21 \mathrm{mM}^{-1} \mathrm{~cm}^{-1}\right)$. The total and soluble proteins have been estimated in the lens by the using method of Lowry et al., 1951 [39]. The reaction has been measured at $540 \mathrm{~nm}$ against the blank and values are calculated from a standard curve of bovine serum albumin. The specific activity of the antioxidant enzyme superoxide dismutase (SOD) was estimated spectrophotometrically [40]. The total reaction was carried out at $25^{\circ} \mathrm{C}$ for 3 minutes, and change in absorbance at $420 \mathrm{~nm}$ with a suitable blank was also recorded. One unit of SOD activity is defined as the amount of the enzyme required to inhibit $50 \%$ of autoxidation of pyrogallol. Catalase (CAT) activity was assayed spectrophotometrically described by earlier described method [41]. The reaction mixture was measured at $570 \mathrm{~nm}$ against control, and the activity was expressed as units per milligram protein (one unit is the amount of enzyme that utilizes $1 \mathrm{mmol}$ of $\mathrm{H}_{2} \mathrm{O}_{2} / \mathrm{min}$ ). GSH peroxidase (GPx) activity was measured using method [42]. Moreover, this assay result depends on the rate of GSH oxidation by $\mathrm{H}_{2} \mathrm{O}_{2}$, as catalyzed by the GPx present in the supernatant and it was read at $430 \mathrm{~nm}$.

\section{Histopathological examination}

For histopathological examinations, eyes have been collected from rats by posterior approach in each experimental group and preserved in $10 \%$ formaldehyde. Formalin-fixed eyes were collected and dehydrated in a graded series of ethanol (70-100\%), cleared in xylene, and finally embedded in paraffin. Thereafter, $5 \mathrm{~mm}$ thin sections were prepared and stained with hematoxylin and eosin ( $\mathrm{H}$ and $\mathrm{E}$ ) for histopathological examination [43]. The photomicrographs of the respective tissue sections were taken using Olympus BX41 research optical microscope fitted with Olympus DP 25 digital camera.

\section{Statistical analysis}

All data have been expressed as the mean \pm SD. Statistical significance was performed by ANOVA followed by Tukey's test and $\mathrm{p} \leq 0.05$, was considered to be statistically significant using SPSS 20 .

\section{RESULTS}

\section{Extraction yield, TPC and TFC}

Table 1 summarizes the percentage of yield of crude successive extracts (ethyl acetate, methanol, petroleum ether, and aqueous) of HI and results revealed that methanol extract found to be higher yield than those of the other extracts. Results of the TPC of various extracts of HI have been significant and shown in Table 1, and it was calculated using the following linear equation based on the calibration curve of gallic acid; $\mathrm{y}=0.0009 \mathrm{x}-0.013, \mathrm{R}^{2}=0.9981$. TFC was calculated as quercetin equivalents as showed in Table 1 . This study showed the highest flavonoid content in the EAHI, and the results have been calculated using the following linear equation based on the calibration curve of quercetin; $y=0.0025 x+0.0681, R^{2}=0.9905$.

\section{Free radical scavenging potential of $\mathrm{HI}$ extracts}

The effects of extracts on different free radicals are represented in Fig. 1. All the extracts demonstrated significant scavenging abilities which varied depending on the solvent/dose used and their results ( $\mathrm{IC}_{50}$ values) have been shown in Table 2. For the DPPH radical, EAHI showed a higher inhibitory potential along with the standard (L-ascorbic acid) as described in Fig. 1a; while for the ABTS assay, the methanol extract of HI (MEHI) showed a higher radical scavenging activity with a low $\mathrm{IC}_{50}$ value $(19.66 \pm 1.01 \mu \mathrm{g} / \mathrm{ml})$ than those of other extracts Table 2 and the results have been expressed as \% inhibition (Fig. 1b). However, all the extracts' has been found to be significant $(\mathrm{p} \leq 0.05)$ in relation to that of ascorbic acids. The results NO scavenging potential of the different extracts and the standard ascorbic acid represented in Fig. 1c. Among them, EAHI showed the highest NO inhibitory potential with a low $\mathrm{IC}_{50}$ value $(167.36 \pm 1.66 \mu \mathrm{g} / \mathrm{ml})$ as compared with standard ascorbic acid $(60.91 \pm 0.79 \mu \mathrm{g} / \mathrm{ml})$ as represented in Table 2. Hydroxyl radical scavenging activity of various extracts has been presented in Fig. 1d, using rutin as standard.

The EAHI extract showed a good activity in depleting $\mathrm{H}_{2} \mathrm{O}_{2}$, with an $\mathrm{IC}_{50}$ value of $198.69 \pm 0.42 \mu \mathrm{g} / \mathrm{ml}$ as compared with well-known flavonoid, rutin $(80.25 \pm 3.15 \mu \mathrm{g} / \mathrm{ml})$ and represented in Table 2. The reductive activities of the various plant extracts are shown in Fig. 2. We noticed that EAHI extract had the higher reducing ability than among other extracts. According to their ability, they can be arranged in order as BHT $>$ EAHI $>\mathrm{MEHI}>\mathrm{AQHI}>$ petroleum ether $\mathrm{HI}$ extracts.

\section{Pharmacological evaluation of HI in STZ induced diabetic rats}

Since EAHI roots showed greater antioxidant potential than among other extracts, we tested its potential further study on diabetes and its complications in STZ induced rodent model. All rats (Group I-IV) have been fed ad libitum, and it was noticed that there was an increase in food intake in all diabetic rats (Group II-IV) compared to the control rats. Despite increased food intake, the body weight of diabetic control rats was found to be low (Group-II 168.03 $\pm 3.36 \mathrm{~g}$ ), in relation to the control rats $(284.55 \pm 0.39 \mathrm{~g}$ ), and HI fed rats (Group III $202.35 \pm 2.53 \mathrm{~g}$ and Group IV $264 \pm 0.82 \mathrm{~g}$ ), respectively.

Fig. 3a demonstrates the levels of blood glucose in diabetic control rats have been significantly higher than in relation to control rats and oral administration of EAHI suppressed the elevated of blood glucose levels, which is significantly lower as compared to diabetic control rats $(p<0.005)$. Control group lenses had no signs and symptoms of cataract development throughout the experimental period; however, cataract progression has been seen in diabetic control rats over a period of 8 weeks, which were significantly delayed cataract progression in rats supplemented with the EAHI (Group III and IV). Fig. 3b has been shown the representative stages of cataract progression and photographs have been showed the opacification of the lens (Fig. 4) at the end of the experiment $\left(8^{\text {th }}\right.$ week).

Effect of EAHI on oxidative stress and enzymatic alterations in lens Further, we assessed oxidative stress by measuring TBARS (a lipid oxidation product), protein carbonyls (oxidative products of protein), 
Table 1: Quantitative analysis of yield, TPC and TFCs in roots of HI, using gallic acid and quercetin as common reference compounds, respectively

\begin{tabular}{llll}
\hline Extract & TPC & TFC & Yield of extraction (\% w/v) \\
& (mg/g GAE of dry extract) & (mg/g QE of dry extract) & 12.8 \\
\hline Methanol & $114.23 \pm 7.31^{*}$ & $44.35 \pm 1.43^{*}$ & 3.9 \\
Ethyl acetate & $94.00 \pm 6.38^{*}$ & $70.24 \pm 4.51^{*}$ & 8.2 \\
Petroleum ether & $10.11 \pm 1.12^{*}$ & $7.65 \pm 0.2^{*}$ & 5.1 \\
Aqueous & $27.34 \pm 4.54^{*}$ & $27.41 \pm 2.07^{*}$ & \\
\hline
\end{tabular}

Values were represented as mean $\pm S D(n=3)$. *Denotes in column are statistically significant $(\mathrm{p} \leq 0.05)$. Values were represented as mean $\pm S D(n=3)$. Superscript *

denotes in column are statistically significant $(\mathrm{p} \leq 0.05)$. GAE: Gallic acid equivalent. QE: Quercetin equivalent, TPC: Total phenolic content, TFC: Total flavonoid content,

HI: Hemidesmus indicus

Table 2: Antioxidant activity of HI roots in different solvents systems

\begin{tabular}{|c|c|c|c|c|c|}
\hline \multirow[t]{2}{*}{ No } & \multirow[t]{2}{*}{ Extraction } & \multicolumn{4}{|c|}{$\mathrm{IC}_{50}$ values $(\mu \mathrm{g} / \mathrm{mL})$} \\
\hline & & DPPH & ABTS & NO & Hydroxyl radical \\
\hline 1 & Ethyl acetate & $46.42 \pm 1.15^{*}$ & $28.77 \pm 3.28 *$ & $167.36 \pm 1.66^{*}$ & $198.69 \pm 0.42 *$ \\
\hline 2 & Methanol & $73.87 \pm 2.26^{*}$ & $19.66 \pm 1.01 *$ & $236.78 \pm 13.54 *$ & $219.83 \pm 7.02 *$ \\
\hline 3 & Pet ether & $158.69 \pm 2.02 *$ & $62.7 \pm 1.12^{*}$ & $425.31 \pm 27.49 *$ & $408.49 \pm 21.6^{*}$ \\
\hline 4 & Aqueous & $94.78 \pm 3.78^{*}$ & $37.94 \pm 1.05^{*}$ & $257.51 \pm 6.93^{*}$ & $266.43 \pm 9.88^{*}$ \\
\hline 5 & L-ascorbic acid & $12.02 \pm 0.22$ & $5.06 \pm 0.09$ & $60.91 \pm 0.79$ & NA \\
\hline 6 & Rutin & NA & NA & NA & $80.25 \pm 3.15$ \\
\hline
\end{tabular}

Values were represented as mean $\pm S D(n=3)$. Denotes statistically significant $(\mathrm{p} \leq 0.05)$ compared with standard. NA: Not analyzed, NO: Nitric oxide,

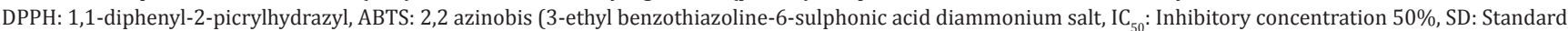
deviation, HI: Hemidesmus indicus
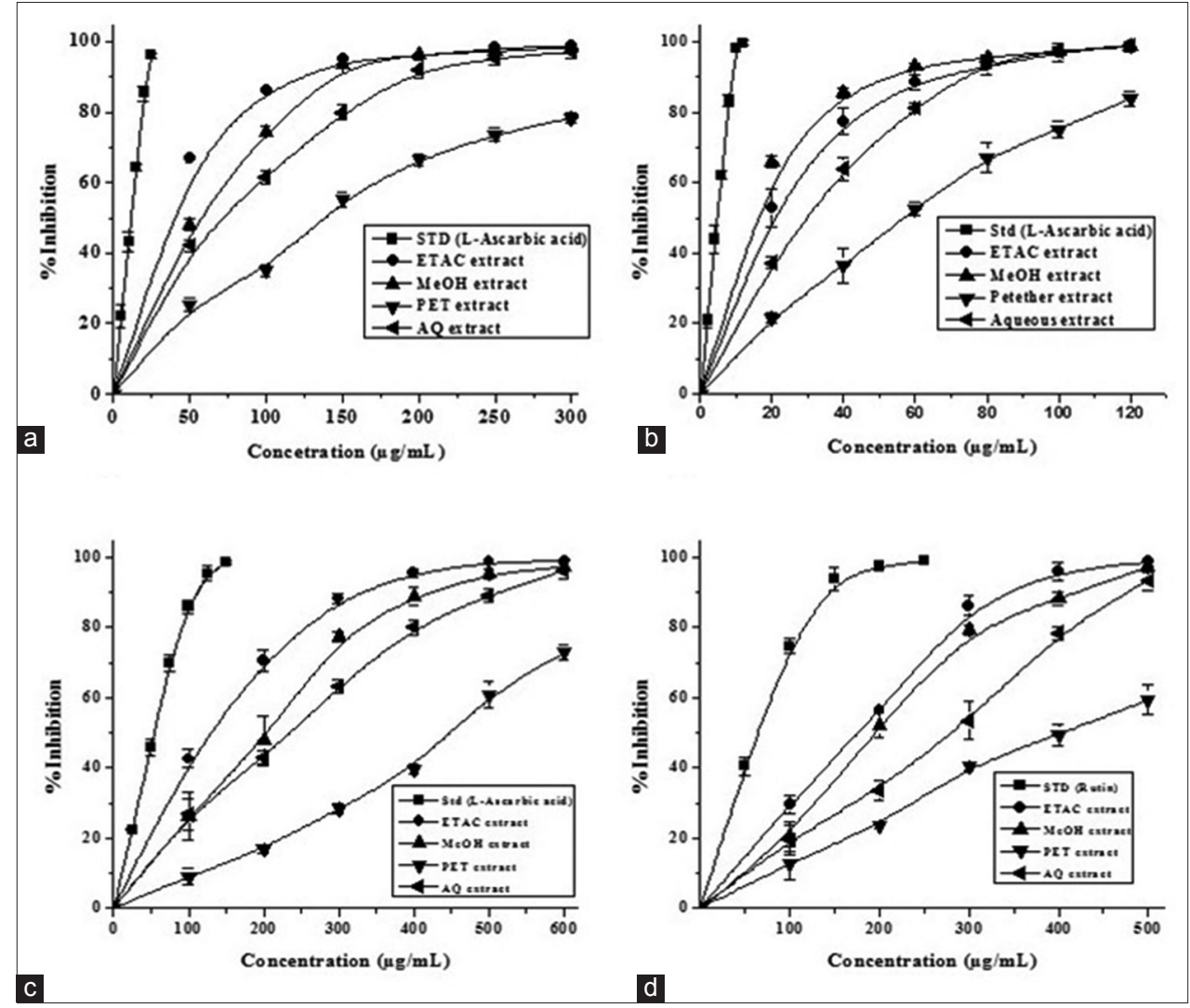

Fig. 1: Percentage scavenging activities of roots of Hemidesmus indicus and its fractions through 1,1-diphenyl-2-picrylhydrazyl (a), 2,2 azinobis (3-ethyl benzothiazoline-6-sulphonic acid diammonium salt (b), nitric oxide (c), and hydroxyl radical (d) assays compared with referenced standards. Data were expressed as mean \pm standard deviation, $(n=3)(p \leq 0.05)$. ETAC: Ethyl acetate, MeOH: Methanol, PET: Petroleum ether, and AQ: Aqueous

GSH (a cellular antioxidant), and antioxidant enzymes such as SOD, CAT, and GSH peroxidase (GPX) in the rodent lens. The levels of TBARS, protein carbonyls have been increased and GSH levels have been reduced in the lenses of diabetic control rats. Interestingly, rat lenses of treated with EAHI prevented lipid and protein oxidation as evidenced by significantly decreased TBARS, protein carbonyls and the loss of GSH (Table 3). Antioxidant enzymes such as SOD, CAT and GPx have been significantly decreased in the lens of diabetic control rats, and their 
enzymatic activities were restored EAHI treated rat lenses, which were significantly higher $(\mathrm{p}<0.05)$ as compared to diabetic groups (Table 3 ).

The underlying mechanism, insolubilization of proteins have been considered to be the ultimate change that results in lens opacification; therefore, we analyzed the total and soluble protein content in all group rat lenses. There was a significant decrease in both total and soluble protein in diabetic control rats compared with the control rats, and supplementation of EAHI rats improved the percentage of soluble protein as showed in Fig. 5.

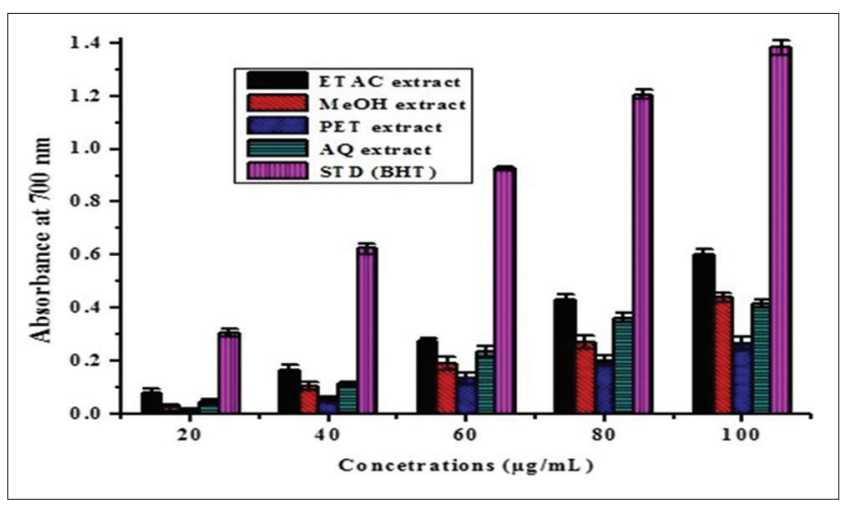

Fig. 2: Antioxidant activity of roots of Hemidesmus indicus through the reducing power assay in different solvent systems and compared with known standard (BHT). Data were expressed as mean \pm standard deviation, $(n=3)(p \leq 0.05)$. ETAC: Ethyl acetate, MeOH: Methanol, PET: Petroleum ether, AQ: Aqueous, and BHT: Butylated hydroxyltoluene
Histopathological evaluation

Histopathological examinations in lens tissues of all rats have been observed using $\mathrm{H}$ and $\mathrm{E}$ stain. The control group rats showed the normal morphology of the lens fibers (Fig. 6a) and were in diabetic control rat lens gain more staining in the area of lens fibers, which are indicating protein aggregation and cataract progression (Fig. 6b). The supplementation of EAHI rat lens (Group III IV) showed lower protein aggregations in lens fibers as control lens. These observations are suggesting that delaying cataract progression and ameliorative effect of EAHI confirmed with dose-dependent (Fig. 6c and d).

\section{DISCUSSION}

Diabetes and hyperglycemia are primary causal factors, play a key role in the onset of diabetic complications such as cataract which contribute to blindness worldwide $[44,45]$. Recent studies reported that diabetes could become a major threat to public health and the management of cataract blindness [46]. Cataract is a long-term complication of diabetes, the only remedy for the treatment of such kind disease is surgery with undesirable defects. Several studies reported that oxidative stress and hyperglycemia have been suggested as common underlying mechanisms of cataractogenesis due to diabetes and augmentation of the antioxidant defenses of the lens have been shown to prevent or delay cataract $[47,48]$. Therefore, any strategy that prevents (or) slow down the progression of cataract can have a significant effect on human health. Since ancient time, medicinal plants are a major source of secondary metabolites, which play a key role in the highly effective free radical scavengers and antioxidant and biological activities [49]. The antioxidant activity of alcoholic extract of HI has been demonstrated earlier in numerous methods [50-52]. However, the potential of free radical scavenging ability of $\mathrm{HI}$ roots in chemical and biological systems has not been comprehensively investigated. In this study, we primarily

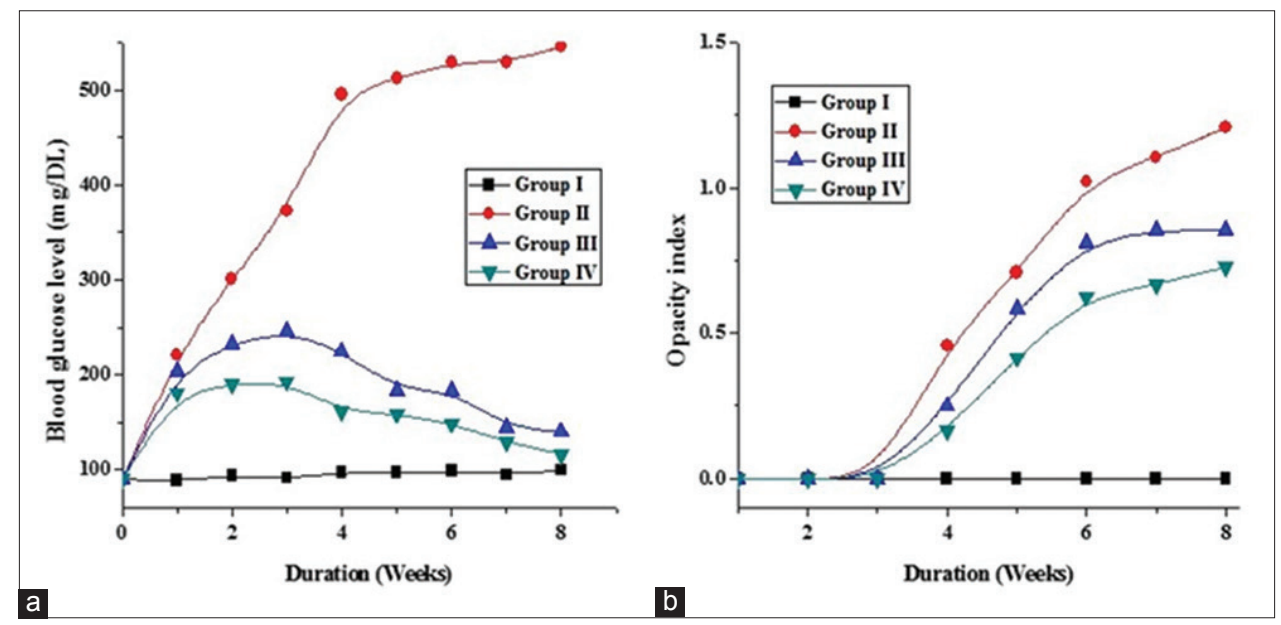

Fig. 3: Ethyl acetate extract of Hemidesmus indicus (EAHI) prevented diabetic cataract progression in streptozotocin induced diabetic in rats. The effect of EAHI on blood glucose levels (a) and grading of cataract progression was performed by slit-lamp examination (b) a weekly basis. The data are the mean \pm standard deviation $(n=6)$

Table 3: Ethyl acetate extract of HI prevented oxidative stress and restoration of antioxidant enzymes in STZ induced diabetic in rat lens

\begin{tabular}{lllc}
\hline Parameters & Group-I & Group-II & Group-III \\
\hline GSH & $14.44 \pm 0.41$ & $6.49 \pm 0.14^{*}$ & $8.27 \pm 0.12^{* \#}$ \\
TBARS & $8.92 \pm 0.41$ & $19.42 \pm 0.89^{*}$ & $14.74 \pm 0.33^{* \#}$ \\
Protein carbonyls & $13.46 \pm 0.29$ & $32.03 \pm 0.63^{*}$ & $23.96 \pm 0.47^{* \#}$ \\
SOD & $4.53 \pm 0.74$ & $1.33 \pm 0.58^{*}$ & $1.86 \pm 0.20^{*}$ \\
CAT & $8.76 \pm 0.57$ & $3.71 \pm 0.24^{*}$ & $5.58 \pm 0.52^{* \#}$ \\
GPx & $24.20 \pm 2.41$ & $16.51 \pm 0.85^{*}$ & $17.67 \pm 0.73^{* \#}$ \\
\hline
\end{tabular}

After 8 weeks duration of experiment, lenses were homogenized and GSH ( $\mu$ mols/g lens), TBARS (nmols/g lens), protein carbonyls (nmols/mg protein),

SOD (units/100 mg of protein/min), CAT (units/100 mg of protein/min), and GPx ( $\mu$ mols of NADPH oxidized/h/100mg of protein) have been estimated. The data are the mean \pm SD $(n=3) . *$ Indicates statistically significant from Group I (analyzed by ANOVA; $\mathrm{p} \leq 0.05)$. "Indicates statistically significant from Group II (analyzed by ANOVA; $\leq$ 0.05). HI: Hemidesmus indicus, GSH: Glutathione 


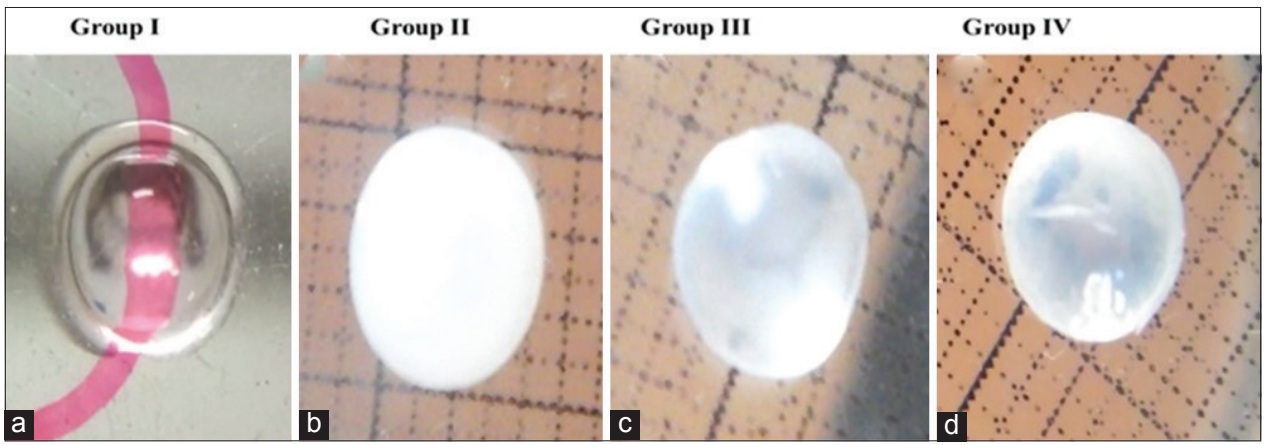

Fig. 4: Photographs show the effect of ethyl acetate extract of Hemidesmus indicus on the delaying of cataract progression in streptozotocin induced rat lenses after 8 weeks post-treatment. (a) Group I, (b) Group II, (c) Group III, and (d) Group IV

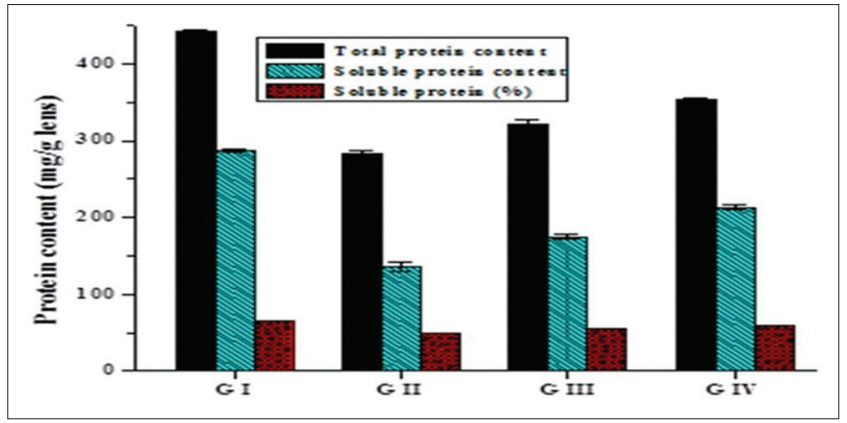

Fig. 5: Effect of ethyl acetate extract of Hemidesmus indicus treatment on the protein content of streptozotocin induced diabetic in rat lens. Values are given as mean \pm standard deviation $(n=3)$
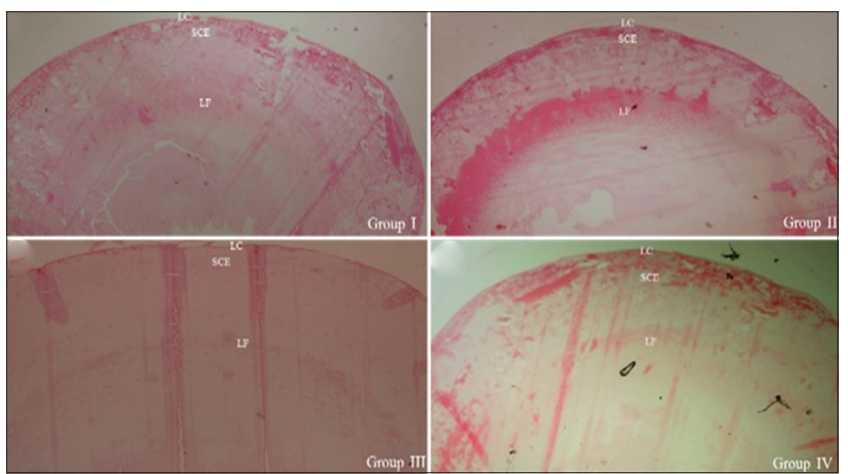

Fig. 6: The end of the experiment eyes were collect and dissected from different groups of rats (Groups I-IV), histopathological studies were performed by Hematoxylin and Eosin stain and examine under a microscope (Olympus CX21) for histological changes

investigated the amount of phytoconstituents (TPC and TFC) and free radical scavenging activity of different extracts of $\mathrm{HI}$ by the methods of $\mathrm{DPPH}, \mathrm{ABTS}, \mathrm{NO}, \mathrm{OH}$, and reducing power in in vitro. The significance of this observation was further investigated the EAHI extract on hyperglycemia and cataract progression in STZ induced diabetic rat model.

In recent times, the search for phytochemicals (phenols and flavonoids) has been rising due to their potential use in the therapy of various chronic and infectious diseases [53]. Looking back to our results it was seen that ethyl acetate most effective solvent for extracting phenolics from HI followed by methanol. The total phenolic and flavonoid contents of the ethyl acetate extraction have been higher than those of methanol, petroleum ether, and aqueous extracts. This result could be explained the high content of total phenolics in EAHI indicated the potent antioxidant properties of this part. In this study, it appeared that the higher TPC and TFC of the plant extracts resulted in higher antioxidant activity which could be attributed to the redox properties such as reducing agents, hydrogen donors, free radical scavenger, singlet oxygen quenchers, and metal chelators [54].

DPPH is a stable free radical and can accept an electron or hydrogen radical to become a durable diamagnetic molecule. All the plant extracts tested inhibited the DPPH radical and result proved that the extracts are in a position to donating an electron or hydrogen which could react with DPPH radical in different levels. This difference could be attributed to an unequal contest of antioxidant molecules such as polyphenol, flavonoids dissolve based on the polarity of solvents. The EAHI had the lowest $\mathrm{IC}_{50}(46.42 \pm 1.15 \mu \mathrm{g} / \mathrm{mL})$ indicates greatest scavenging activity compared with other extracts. Moreover, antiradical activity of the extracts to trap DPPH radical depends on the availability and the ability of these extracts act as proton donors to the presence of polyphenols content [55]. ABTS is oxidized by potassium persulfate to its cation radical $\mathrm{ABTS}^{+}$, which is intensely colored. Our results showed that all the tested samples demonstrated a scavenging potential of the ABTS with varying inhibitory potential and interestingly, the MEHI demonstrating the highest ABTS inhibitory power and this result confirmed that the presence of higher phenolic level in the extract justified its highest scavenging property on ABTS radical [56]. Eventually, a good relationship was also observed between phenolics and antioxidant activity which further confirms this view [57]. NO is an important chemical mediator that is involved in several biological processes, and an elevated production of NO could lead to several diseases. According to this study, EAHI showed higher NO radical scavenging power while remaining extracts depending on their phenolic composition. Earlier studies reported that the antioxidant activity of phenolic acids is related to the quantity, number, and position of hydroxyl groups in the molecule [58]. Hydroxyl radicals are highly reactive in nature, and it's capable to damage biological molecules such as DNA, lipids, and proteins to increase oxidative damage in the human body [59]. Our results demonstrated that EAHI exhibited a highest $\mathrm{OH}$ scavenging power compared with other extracts. It can, therefore, be assumed that these extracts have good antioxidant properties. Studies recommended several testing methods for the investigation of antioxidant activity of extracts from natural resources [60]. Regarding our results, EAHI exhibited highest reductive activity at different concentrations, and this extract has good electron donors for power reducing activity. Overall results conclude that, among four different extracts employed in this present study, EAHI showed significant antioxidant activity. Moreover, studies have also been extended to know the efficacy of EAHI root in STZ induced diabetic rats.

STZ is a chemical agent used to induce hyperglycemia in experimental animals mainly due to the rampant generation of ROS, selective pancreatic islet b-cell cytotoxicity and the cytotoxic events subsequently cause b-cell necrosis $[61,62]$. In this study, STZ 
significantly induced hyperglycemia, and oral administration of the EAHI (200 and $400 \mathrm{mg} / \mathrm{kg}$ body weight) for 8 weeks affected a significant decrease in blood glucose levels and gain body weight. STZ induced is characterized by a severe loss of body weight which was observed in diabetic control rats and EAHI treated rats (Group III and IV) showed significant improvement in body weight ( $\leq \leq 0.05)$ when compared with diabetic control rats. The loss of body weight in diabetic control rats might be the results of protein wasting due to unavailability of carbohydrate for utilization as an energy source [63]. The present study confirms the antihyperglycemic property of HI roots in STZ induced diabetic rats. Administration of crude of EAHI at a dosage of (200 and $400 \mathrm{mg} / \mathrm{kg}$ body weight) tended to bring blood glucose levels toward near normal levels. However, the extract did not produce any hypoglycemic effect in normal rats. Hence, the EAHI may be considered to have a good antihyperglycemic active principle(s) without causing any hypoglycemic effect unlike insulin, and other synthetic drugs and the safe dose for HI administration has been reported previously [25]. However, the serum glucose level of diabetic rats treated with $\mathrm{HI}$ is still high and is more than the threshold $(150 \mathrm{mg} / \mathrm{dl})$ that is necessary for the induction of cataract [64]. Our results indicate that cataract was established in the diabetic group after the $5^{\text {th }}$ week of STZ injection and progressed up to the end of the study. However, the significant decrease in the cataract score is seen in Group III and IV due to the EAHI administration. Therefore, the observed delay of the onset cataract progression of after the administration of $\mathrm{HI}$ in diabetic rats is possibly due to other factors in addition to its glucose lowering property. To investigate this hypothesis, numerous biochemical pathways related to the formation of diabetic cataract have been investigated.

During the progression of the cataract, the total and soluble protein content of the diabetic lenses was reduced significantly. The reduction may be caused by the formation of high molecular weight aggregates of proteins, oxidative stress, cross-linking of proteins, and protein leakage from osmotic stress $[65,66]$. As our results, the treatment of rats with HI considerably prevented the total and soluble protein loss in diabetic lenses. The present study showed that increase in protein carbonyls, TBARS and decreased GSH levels may be assigned to oxidative stress in diabetic control rat lenses. Moreover, then treated with EAHI have been proven to prevent accumulation of TBARS and protein carbonyls and preventing the loss of GSH. Further, altered activities of the antioxidant enzymes, including SOD, CAT, and GPx are due to the increase of oxidative stress in diabetic conditions as reported previously [67]. Our results demonstrate that the EAHI, with its antioxidant activities, could significantly increase the activity of SOD, CAT, and GPx enzymes in diabetic lenses. The decrease of enzymes activities in the diabetic control group suggests that the molecules responsible for the antioxidant enzyme activities in that medium were exhausted by the higher concentration of the oxidants [68] and these results agreement with earlier reports [69]. Furthermore, the histopathological examination showed that the treatment of diabetic rats with lower and higher doses of EAHI extracts protected the lens structures.

\section{CONCLUSION}

Extracts of $\mathrm{HI}$ have a good amount of polyphenolics, and significant free radical scavenging ability. After completion of the primary study, we selected EAHI to further investigation on antioxidant, antihyperglycemic, and anticataract potential in the STZ induced diabetic rats. Overall results confirmed the antioxidant activities of $\mathrm{HI}$ root extract led to inhibition of physiological, molecular and histopathological alterations in diabetic rats. Nevertheless, further studies need to be investigated to isolate and characterize the bioactive compounds responsible for these activities and its constituents as promising therapeutic agents for DM and its complications.

\section{ACKNOWLEDGMENTS}

One of the authors, TP, sincerely thanks, BSR (RFSMS) fellowship received from UGC (F.7-143/2007/BSR. Date: 28-03-2014) and also acknowledges to DRS Lab, Department of Zoology (UGC), for providing lab facility.

\section{REFERENCES}

1. Brownlee M. Lilly Lecture 1993. Glycation and diabetic complications. Diabetes 1994:43(6):836-41.

2. Congdon NG, Friedman DS, Lietman T. Important causes of visual impairment in the world today. JAMA 2003;290(15):2057-60.

3. Nirmalan PK, Robin AL, Katz J, Tielsch JM, Thulasiraj RD, Krishnadas R, et al. Risk factors for age related cataract in a rural population of Southern India: The Aravind Comprehensive Eye Study. Br J Ophthalmol 2004;88(8):989-94.

4. King H, Aubert RE, Herman WH. Global burden of diabetes, 1995-2025: Prevalence, numerical estimates, and projections. Diabetes Care 1998;21(9):1414-31.

5. Kumar PA, Suryanarayana P, Reddy PY, Reddy GB. Modulation of alpha-crystallin chaperone activity in diabetic rat lens by curcumin. Mol Vis 2005;11:561-8.

6. Yokozawa T, Cho EJ, Park CH, Kim JH. Protective effect of proanthocyanidin against diabetic oxidative stress. Evid Based Complement Alternat Med 2012;2012:623879.

7. Sreeja S, Pjayanthi G, Devi SG. Status of enzymatic antioxidants in eye lens extracted from cataractous subjects. Int J Pharm Pharm Sci 2015;7(3):4.

8. Süleyman H, Demircan B, Karagöz Y. Anti-inflammatory and side effects of cyclooxygenase inhibitors. Pharmacol Rep 2007;59(3):247-58.

9. Halliwell B, Gutteridge JM. Role of free radicals and catalytic metal ions in human disease: An overview. Methods Enzymol 1990;186:1-85.

10. Aiyegoro OA, Okoh AI. Preliminary phytochemical screening and in vitro antioxidant activities of the aqueous extract of Helichrysum longifolium DC. BMC Complement Altern Med 2010;10:21.

11. Wu YY, Li W, Xu Y, Jin EH, Tu YY. Evaluation of the antioxidant effects of four main theaflavin derivatives through chemiluminescence and DNA damage analyses. J Zhejiang Univ Sci B 2011;12(9):744-51.

12. Bruckner J. In: Hudson, BJ., editor. Food Antioxidants. Zahlr. Abb. und Tab. Vol. 36. London, New York: Elsevier Applied Science; 1990. p. 317,515 .

13. Moukette BM, Pieme CA, Njimou JR, Biapa CP, Marco B, Ngogang Y. In vitro antioxidant properties, free radicals scavenging activities of extracts and polyphenol composition of a non-timber forest product used as spice: Monodora myristica. Biol Res 2015;48:15

14. Shahidi F, Naczk M. Place. Phenolics in Food and Nutraceuticals. Boca Raton, FL: CRC Press; 2003

15. Gucin I, Oktay M, Kıreccı E, Kufrevioglu OI. Screening of antioxidant and antimicrobial activities of anise (Pimpinella anisum L.) Seed extracts. Food Chem 2003;83(3):371-82.

16. Alam MN, Bristi NJ, Rafiquzzaman M. Review on in vivo and in vitro methods evaluation of antioxidant activity. Saudi Pharm J 2013;21(2):143-52.

17. Kumaran A, Karunakaran RJ. In vitro antioxidant activities of methanol extracts of five Phyllanthus species from India. LWT Food Sci Technol 2007;40(2):344-52.

18. Austin A. A review on Indian sarsaparilla, Hemidesmus indicus (L.) R. Br. J Biosci 2008;8(1):1-12.

19. Verma PR, Joharapurkar AA, Chatpalliwar VA, Asnani AJ. Antinociceptive activity of alcoholic extract of Hemidesmus indicus R. Br. In mice. J Ethnopharmacol 2005;102(2):298-301.

20. Das S, Prakash R, Devaraj SN. Antidiarrhoeal effects of methanolic root extract of Hemidesmus indicus (Indian sarsaparilla) - an in vitro and in vivo study. Indian J Exp Biol 2003;41(4):363-6.

21. Das S, Devaraj SN. Antienterobacterial activity of Hemidesmus indicus R. Br. Root extract. Phytother Res 2006;20(5):416-21

22. Baheti JR, Goyal RK, Shah GB. Hepatoprotective activity of Hemidesmus indicus R. Br. In rats. Indian J Exp Biol 2006;44(5):399-402.

23. Saravanan N, Nalini N. Hemidesmus indicus protects against ethanolinduced liver toxicity. Cell Mol Biol Lett 2008;13(1):20-37.

24. Gayathri M, Kannabiran K. Hypoglycemic activity of Hemidesmus indicus $\mathrm{R}$. Br. On streptozotocin-induced diabetic rats. Int J Diabetes Dev Ctries 2008;28(1):6-10.

25. Mahalingam G, Kannabiran K. Hemidesmus indicus root extract ameliorates diabetes-mediated metabolic changes in rats. Int J Green Pharm 2009;3(4):314-8.

26. Nadkarni KM, Nadkarni AK. Place. Indian Materia Medica. Bombay: Popular Book Depot; 1955

27. Rajan S, Shalini R. Antidiarrhoeal activity of aqueous and alcoholic extracts of Hemidesmus indicus root. Int J Pharm Pharm Sci 2015;7(3):4. 
28. Diaz MN, Frei B, Vita JA, Keaney JF Jr. Antioxidants and atherosclerotic heart disease. N Engl J Med 1997;337(6):408-16.

29. Ainsworth EA, Gillespie KM. Estimation of total phenolic content and other oxidation substrates in plant tissues using Folin-Ciocalteu reagent. Nat Protoc 2007;2(4):875-7.

30. Halliwell B, Gutteridge JM, Aruoma OI. The deoxyribose method: A simple "test-tube" assay for determination of rate constants for reactions of hydroxyl radicals. Anal Biochem 1987;165(1):215-9.

31. Huang MH, Huang SS, Wang BS, Wu CH, Sheu MJ, Hou WC, et al. Antioxidant and anti-inflammatory properties of Cardiospermum halicacabum and its reference compounds ex vivo and in vivo. J Ethnopharmacol 2011;133(2):743-50.

32. Sadeghi Z, Valizadeh J, Azyzian Shermeh O, Akaberi M. Antioxidant activity and total phenolic content of Boerhavia elegans (choisy) grown in Baluchestan, Iran. Avicenna J Phytomed 2015;5(1):1-9.

33. Srinivasan R, Chandrasekar MJ, Nanjan MJ, Suresh B. Antioxidant activity of Caesalpinia digyna root. J Ethnopharmacol 2007;113:284-91.

34. Matkowski A, Piotrowska M. Antioxidant and free radical scavenging activities of some medicinal plants from the Lamiaceae. Fitoterapia 2006;77(5):346-53.

35. Yildirim A, Mavi A, Oktay M, Kara AA, Algur OF, Bilaloglu V. Comparison of antioxidant and antimicrobial activities of tilia (Tilia argentea Desf ex DC), sage (Salvia triloba 1.), and black tea (Camellia sinensis) extracts. J Agric Food Chem 2000;48(10):5030-4.

36. Ellman GL. Tissue sulfhydryl groups. Arch Biochem Biophys 1959;82(1):70-7.

37. Matsunami T, Sato Y, Sato T, Yukawa M. Antioxidant status and lipid peroxidation in diabetic rats under hyperbaric oxygen exposure. Physiol Res 2010;59(1):97-104.

38. Uchida K, Kanematsu M, Sakai K, Matsuda T, Hattori N, Mizuno Y, et al. Protein-bound acrolein: Potential markers for oxidative stress. Proc Natl Acad Sci U S A 1998;95(9):4882-7.

39. Lowry OH, Rosebrough NJ, Farr AL, Randall RJ. Protein measurement with the Folin phenol reagent. J Biol Chem 1951;193(1):265-75.

40. Marklund S, Marklund G. Involvement of the superoxide anion radical in the autoxidation of pyrogallol and a convenient assay for superoxide dismutase. Eur J Biochem 1974;47(3):469-74.

41. Sinha AK. Colorimetric assay of catalase. Anal Biochem 1972;47(2):389-94.

42. Lawrence RA, Sunde RA, Schwartz GL, Hoekstra WG. Glutathione peroxidase activity in rat lens and other tissues in relation to dietary selenium intake. Exp Eye Res 1974;18(6):563-9.

43. Bancroft JD, Floyd AD, Suvarna SK. Bancroft's Theory Practice of Histological Techniques. $7^{\text {th }}$ ed. UK: Elsevier Health; 2013. p. 654.

44. Peyroux J, Sternberg M. Advanced glycation endproducts (AGEs): Pharmacological inhibition in diabetes. Pathol Biol (Paris) 2006;54(7):405-19.

45. Abraham AG, Condon NG, West Gower E. The new epidemiology of cataract. Ophthalmol Clin North Am 2006;19(4):415-25.

46. Kyselova Z, Stefek M, Bauer V. Pharmacological prevention of diabetic cataract. J Diabetes Complications 2004;18(2):129-40.

47. Varma SD, Hegde KR. Effect of alpha-ketoglutarate against selenite cataract formation. Exp Eye Res 2004;79(6):913-8.

48. Srivastava Y, Venkatakrishna-Bhatt H, Verma Y. Effect of Momordica charantia Linn. Pomous aqueous extract on cataractogenesis in murrin alloxan diabetics. Pharmacol Res Commun 1988;20(3):201-9.

49. Wei SD, Zhou HC, Lin YM. Antioxidant activities of extract and fractions from the hypocotyls of the mangrove plant Kandelia candel. Int J Mol Sci 2010;11(10):4080-93

50. Ravishankara MN, Shrivastava N, Padh H, Rajani M. Evaluation of antioxidant properties of root bark of Hemidesmus indicus $\mathrm{R}$. Br.
(Anantmul). Phytomedicine 2002;9:153-60

51. Jayaram S, Dharmesh SM. Assessment of antioxidant potentials of free and bound phenolics of Hemidesmus indicus (L) R. Br against oxidative damage. Pharmacognosy Res 2011;3(3):225-31.

52. Mary NK, Achuthan CR, Babu BH, Padikkala J. In vitro antioxidant and antithrombotic activity of Hemidesmus indicus (L) R. Br. J Ethnopharmacol 2003;87(2-3):187-91.

53. Qian ZJ, Jung WK, Byun HG, Kim SK. Protective effect of an antioxidative peptide purified from gastrointestinal digests of oyster, Crassostrea gigas against free radical induced DNA damage. Bioresour Technol 2008;99(9):3365-71

54. Jafri L, Saleem S, Ihsan ul H, Ullah N, Mirza B. In vitro assessment of antioxidant potential and determination of polyphenolic compounds of Hedera nepalensis K. Koch. Arab J Chem 2017;10(2):3699-706.

55. Panda SK. Assay guided comparison for enzymatic and non-enzymatic antioxidant activities with special reference to medicinal plants. In: El-Missiry MA, editor. Antioxidant Enzyme. Ch. 15. Rijeka: InTech; 2012.

56. Biskup I, Golonka I, Gamian A, Sroka Z. Antioxidant activity of selected phenols estimated by ABTS and FRAP methods. Postepy Hig Med Dosw (Online) 2013;67:958-63.

57. Imran M, Khan H, Shah M, Khan R, Khan F. Chemical composition and antioxidant activity of certain Morus species. J Zhejiang Univ Sci B 2010;11(12):973-80.

58. Polterait $\mathrm{O}$. Antioxidants and free radical scavengers of natural origin. Curr Org Chem 1997;1(4):415-40.

59. Anand T, Naika M, Swamy MS, Khanum F. Antioxidant and dna damage preventive properties of Bacopa monniera (1) Wettst. Free Radic Antioxid 2011;1(1):84-90.

60. Kulisic T, Radonic A, Katalinic V, Milos M. Use of different methods for testing antioxidative activity of oregano essential oil. Food Chem 2004;85(4):633-40.

61. Szkudelski T. The mechanism of alloxan and streptozotocin action in B cells of the rat pancreas. Physiol Res 2001;50:537-46.

62. Haluzík M, Nedvídková J. The role of nitric oxide in the development of streptozotocin-induced diabetes mellitus: Experimental and clinical implications. Physiol Res 2000;49 Suppl 1:S37-42.

63. Virdi J, Sivakami S, Shahani S, Suthar AC, Banavalikar MM, Biyani MK. Antihyperglycemic effects of three extracts from Momordica charantia. J Ethnopharmacol 2003;88(1):107-11.

64. Bahmani F, Bathaie SZ, Aldavood SJ, Ghahghaei A. Glycine therapy inhibits the progression of cataract in streptozotocin-induced diabetic rats. Mol Vis 2012;18:439-48.

65. Luthra M, Balasubramanian D. Nonenzymatic glycation alters protein structure and stability. A study of two eye lens crystallins. J Biol Chem 1993;268(24):18119-27

66. Suryanarayana P, Saraswat M, Mrudula T, Krishna TP, Krishnaswamy K, Reddy GB. Curcumin and turmeric delay streptozotocin-induced diabetic cataract in rats. Invest Ophthalmol Vis Sci 2005;46(6):2092-9.

67. Zhang S, Chai FY, Yan H, Guo Y, Harding JJ. Effects of N-acetylcysteine and glutathione ethyl ester drops on streptozotocin-induced diabetic cataract in rats. Mol Vis 2008;14:862-70.

68. Moukette B, Anatole PC, Biapa CP, Njimou JR, Ngogang JY. Free radicals quenching potential, protective properties against oxidative mediated ion toxicity and HPLC phenolic profile of a Cameroonian spice: Piper guineensis. Toxicol Rep 2015;2:792-805.

69. Afolabi IS, Osikoya IO, Fajimi OD, Usoro PI, Ogunleye DO, BisiAdeniyi T, et al. Solenostemon monostachyus, Ipomoea involucrata and Carica papaya seed oil versus glutathione, or Vernonia amygdalina: Methanolic extracts of novel plants for the management of sickle cell anemia disease. BMC Complement Altern Med 2012;12(1):262. 